\title{
Cardiovascular system and COVID-19: manifestations and therapeutics
}

\author{
Ajay K. Mahenthiran ${ }^{1}$, Ashorne K. Mahenthiran ${ }^{2}$ and Jo Mahenthiran ${ }^{1, *}$ \\ ${ }^{1}$ Community Heart and Vascular Hospital, Indianapolis, IN 46250, USA \\ ${ }^{2}$ Feinberg School of Medicine, Northwestern University, Chicago, IL 60611 , USA \\ ${ }^{*}$ Correspondence: jmahenthiran@ecommunity.com (Jo Mahenthiran)
}

DOI: $10.31083 /$ i.rcm.2020.03.124

This is an open access article under the CC BY 4.0 license (https://creativecommons.org/licenses/by/4.0/).

The world is currently in the midst of a daunting global pandemic due to SARS-CoV-2 viral infection and associated COVID-19 disease. Healthcare professionals are tasked with the challenge of managing diverse multisystem clinical manifestations of this infection. Although acute hypoxic respiratory failure is the hallmark of severe COVID19 disease, there have been diverse manifestations within the cardiovascular (CV) system that each pose unique therapeutic challenges. Of these manifestations, myocardial injury and right ventricular dysfunction are the most common, however, heart failure, circulatory shock, cardiomyopathy, arrhythmia, and vascular thrombosis have been noted as well. Furthermore, these CV related manifestations portend greater morbidity and mortality, which requires clinicians to be familiar with the most recent information to provide informed patient care. Although there are limited treatment options available for COVID-19, it is imperative that the potential cardiovascular implications of these therapies are considered in these patients. This review highlights the pathophysiological mechanisms of and therapeutics for CV manifestations of COVID-19 as well as the CV implications of proposed COVID-19 therapies. Since our hospital-based providers are the frontline caregivers battling this pandemic, the aim of this review is to assist with clinical decision-making for optimal patient outcomes while maintaining a safe environment for healthcare personnel.

\section{Keywords}

Coronavirus; COVID-19; cardiovascular system; cardiac injury; heart failure; myocarditis; myocardial infarction; cardiac therapy; arrhythmia, thrombosis

\section{Introduction}

The first severe acute respiratory syndrome (SARS) epidemic caused by a coronavirus (CoV) emerged from China in 2003, called SARS-CoV; which was followed by a second outbreak emerging from Saudi Arabia in 2012, known as Middle Eastern respiratory syndrome (MERS) (He et al., 2020). The current novel CoV Disease of 2019 (COVID-19) is caused by SARS-CoV-2, and was declared a pandemic by the World Health Organization in
March of 2020 (World Health Organization. , 2020a). It is thought to have been transmitted from bats to humans via pangolins (Zhang et al., 2020). Since the outbreak of the infection in December of 2019 from its original epicenter in Wuhan City, China, the virus has spread across the globe through person-to-person transmission via respiratory droplets (Li et al., 2020). As of mid-July 2020, the pandemic is spreading and ongoing with over 14 million affected worldwide, over 3.7 million affected in the United States, and over 602,000 deaths globally (Johns Hopkins University. , 2020).

\section{Background of coronavirus (CoV)}

Coronaviruses are a large family of single positive-strand RNA viruses that infect humans and animals. There are four subclasses of $\mathrm{CoV}$ with varying targets of infection; alpha and beta infect mammals, gamma infect avians and delta can infect both mammals and avians (Ge et al., 2013). The SARS-CoV-2 belongs to the beta subclass (Pal et al., 2020) and is made of four structural proteins: the nuclear protein $(\mathrm{N})$, the spike protein $(\mathrm{S})$, the envelope protein (E), and the membrane protein (M) (Ge et al., 2013). SARS-CoV-2 infection is caused by the binding of the human angiotensin-converting enzyme 2 (ACE2) peptidase to the viral surface spike protein following activation of the spike protein by transmembrane protease serine 2 (TMPRSS2) (see Fig. 1) (Guzik et al., 2020). As evidenced in the mouse heart, the primary function of ACE2 as a peptidase is the metabolism of angiotensin II (ANG II) to angiotensin 1-7 (ANG-(1-7)). The binding of ACE2 to SARS-CoV-2 prevents metabolism and allows for an increased ANG II to ANG-(1-7) ratio, which is detrimental to cardiac function (Chappell, 2016). Furthermore, ACE2 peptidase is expressed in type II alveolar cells, stratified epithelial cells of the upper airway and esophagus, enterocytes of the ileum and colon, myocardial cells, vascular endothelial cells, proximal tubules of the kidney, and urothelial cells (Xu et al., 2020). This leads to greater multi-organ involvement of this infection beyond the alveolar cells of the lungs, including the cardiovascular (CV) system.

\section{Demographics and Non-CV clinical manifestations}

COVID-19 has a greater predilection for severe disease among older patients (median age of 62 years) and males (60\%) (Huang et al., 2020). In addition, there has recently been an increasing in- 


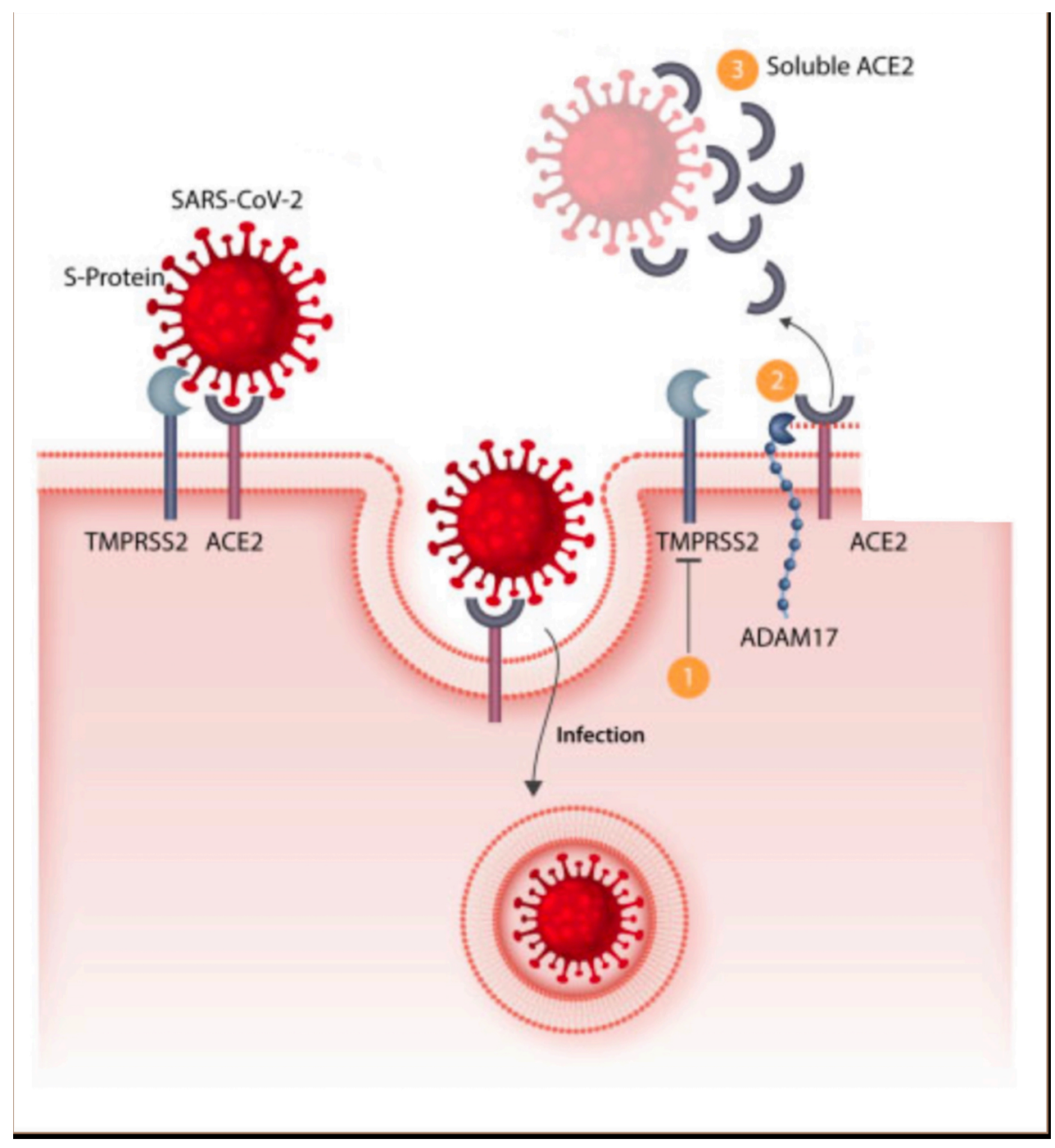

Fig. 1. "Basic pathobiology of SARS-CoV-2 infection and possible treatment strategies". Upon the viral spike protein priming by the transmembrane protease serine 2 (TMPRSS2), SARS-CoV-2 uses the host angiotensin-converting enzyme 2 (ACE2) to enter and infect the cell. Inhibiting TMPRSS2 activity could be used to prevent proteolytic cleavage of the SARS-CoV-2 spike protein and protect the cell against virus--cell fusion (1). Another approach could be neutralizing the virus from entering cells and keeping it in solution by activation of a disintegrin and metalloprotease 17 (ADAM17) which leads to shedding of the membrane-bound ACE2 and release of the soluble extracellular domain of ACE2 (2); additionally, administration of soluble recombinant human ACE2 protein acting as a competitive interceptor for SARS-CoV-2 (3).

Title, legend (modified), image (modified) reproduced with permission from Guzik et al. (2020).

cidence of infection among pediatric patients and young adults $(<$ 39 years) and of severe disease in infants (Stokes et al., 2020). In a recent United States patient sample, the most common comorbidities were hypertension (56\%), obesity (41\%), diabetes (33\%), while coronary artery disease and congestive heart failure were notable CV comorbidities with more severe outcomes (Richardson et al., 2020). Additionally, immunocompromised patients as well as patients with sickle cell disease and/or blood group A are predisposed to poorer outcomes when infected with COVID-19 (Ellinghaus et al., 2020). There is a wide spectrum of clinical manifestations that are known, ranging from an asymptomatic state to severe acute hypoxic respiratory failure with circulatory shock (Guzik et al., 2020). A detailed review of COVID-19 related infection is beyond the scope of this article. Fig. 2 has been reproduced from a previously published article to provide a broad outline of the time course, key clinical manifestations, biological markers and radiological features of the disease (Guzik et al., 2020).

\section{CV-specific manifestations of COVID-19}

Pre-existing CV disease may potentially increase the risk of severe infection and mortality with SARS-CoV-2 (Guan et al., 2020). In addition, variable acute CV manifestations have been reported, with an incidence of $12 \%$ to $28 \%$ on average and up to $31 \%$ among patients in the intensive care unit (ICU) (Wu and McGoogan, 2020). The pathogenesis of CV manifestation in COVID19 may be a primary phenomenon or a secondary response to severe systemic inflammation and hypoxic acute respiratory distress syndrome (ARDS)(Akhmerov and Marbán, 2020). 


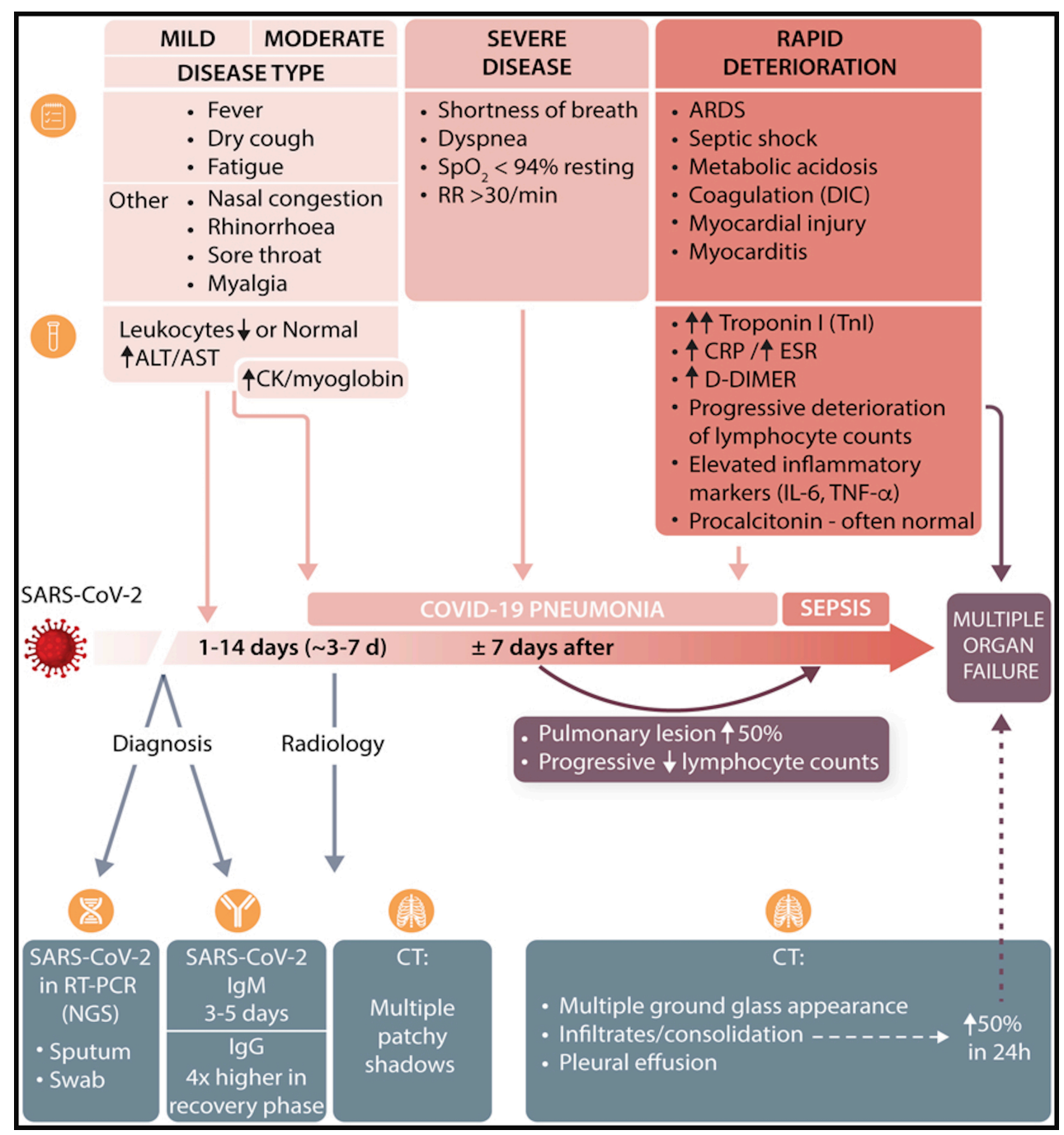

Fig. 2. "Key symptoms, biochemical and radiological features of the clinical course of COVID-19"

Title, image reproduced with permission from Guzik et al. (2020).

\subsection{Myocardial injury}

The most common reported acute $\mathrm{CV}$ manifestation is cardiac injury; as identified by elevated high-sensitivity troponin I, troponin $\mathrm{T}$ and creatinine kinase levels; specifically, high-sensitivity troponin I was significantly elevated in over half of fatal COVID19 cases (Januzzi, 2020). Electrocardiogram (ECG) abnormalities of ST elevation and diffuse ST and/or T-wave abnormalities of ischemia are seen in up to $60 \%$ of COVID-19 patients with myocardial injury (Guzik et al., 2020; Wu and McGoogan, 2020). For COVID-19 patients with ST-elevation myocardial infarction (STEMI), only $60 \%$ of patients who underwent coronary angiography had atherosclerotic plaque rupture leading to thrombotic obstructive coronary artery disease (CAD) (STEMItype $1 \mathrm{MI})$ (Bangalore et al., 2020). This suggests a higher incidence of non-obstructive CAD with STEMI in COVID-19 patients (Bangalore et al., 2020). Among COVID-19 patients with non-obstructive coronary disease, ST elevation secondary to myocardial injury still resulted in a worse prognosis (Bangalore et al., 2020). Other proposed mechanisms of cardiac injury include hypoxic myocardial oxygen supply/demand mismatch (Type
$2 \mathrm{MI}$ ), cytokine storm, coronary spasm, dysregulation of the renin-angiotensin-aldosterone system (RAAS), vascular endothelial damage, and microvascular thrombi (Fried et al., 2020). In addition, pro-inflammatory cytokine storm and/or direct viral seeding can lead to myocarditis (Gupta et al., 2020). Specifically, it has already been demonstrated that in vitro, COVID-19 can directly infect human heart muscle (Sharma et al., 2020) and in vivo, COVID19 can localize to the myocardium causing injury (Tavazzi et al., 2020). As a result of myocardial injury, patients can develop stress cardiomyopathy, left ventricular (LV) systolic dysfunction, circulatory collapse with shock, cardiac arrhythmia and rarely, sudden myocardial rupture (Akhmerov and Marbán, 2020; Arentz et al., 2020; Fried et al., 2020).

\subsection{Heart Failure, cardiomyopathy, and shock}

Limited data exists on the incidence of heart failure in COVID19. Studies from Wuhan City suggest that 50\% of COVID-19 patients who ultimately died had heart failure (HF) (Zhou et al., 2020). Elderly patients with pre-existing CV disease may have LV hypertrophy and diastolic dysfunction that exacerbates the incidence of HF with preserved ejection fraction (HFpEF) (Mehra 


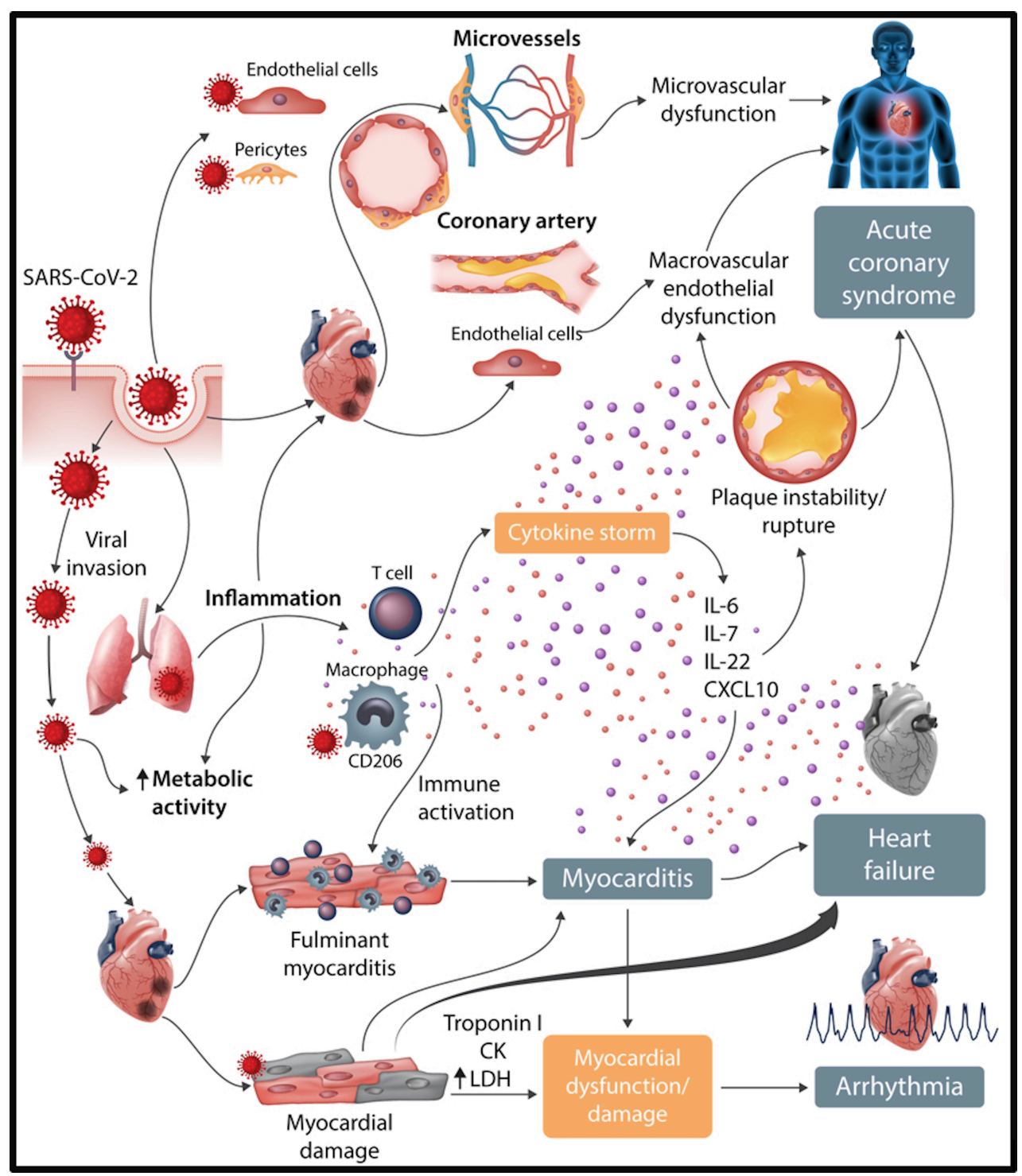

Fig. 3. "Cardiovascular involvement in COVID-19---key manifestations and hypothetical mechanisms". SARS-CoV-2 anchors on transmembrane ACE2 to enter the host cells including cardiac myocytes, leading to inflammation. In particular, the infection of endothelial cells or pericytes could lead to severe micro vascular and macro vascular dysfunction. Furthermore, in conjunction with the immune over-reactivity, it can potentially destabilize atherosclerotic plaques and explain the development of the acute coronary syndromes. Progression of systemic inflammation and immune cell over activation, leading to a 'cytokine storm', which results in an elevated level of cytokines such as IL-6, IL-7, IL-22, and CXCL10. Subsequently, it is possible that activated $\mathrm{T}$ cells and macrophages may infiltrate infected myocardium, resulting in the development of fulminant myocarditis and severe cardiac damage. Similarly, the viral invasion could cause cardiac myocyte damage directly leading to myocardial dysfunction and contribute to the development of arrhythmia.

Title, legend (modified), image reproduced with permission from Guzik et al. (2020).

and Ruschitzka, 2020). Therapeutic interventions utilized to treat COVID-19 infection such as intravenous (IV) fluids, steroids and non-steroidal anti-inflammatory agents can alter salt and water balance, which further aggravates the incidence of HFpEF (Mehra and Ruschitzka, 2020). HF with reduced ejection fraction (HFrEF) may be due to exacerbation of pre-existing or undiagnosed heart disease and/or secondary to acute myocardial injury (Mehra and Ruschitzka, 2020).This can lead to severe circulatory collapse and shock at various stages of the infection. Isolated right heart failure and associated pulmonary hypertension should also be considered in the presence of parenchymal lung injury with hypoxia (Kim,
2020). A recent echocardiographic study suggests right ventricular (RV) dilatation and dysfunction (39\%) followed by LV diastolic (16\%) and LV systolic (10\%) dysfunction were seen in hospitalized patients (Szekely et al., 2020). Additionally, there have been reports of a few SARS-CoV-2 patients with small pericardial effusions and a rare incidence of cardiac tamponade as a result of myopericarditis (Dabbagh et al., 2020). ARDS from COVID-19 infection can cause elevated brain natriuretic peptide (BNP) and/or $\mathrm{N}$-terminal pro BNP levels that may be indicative of a worse disease course (Januzzi, 2020). 
Table 1. Outline of common therapeutic approaches to CV manifestations of COVID-19

\begin{tabular}{lc}
\hline CV Manifestations & Therapeutic Options \\
\hline Cardiac Injury (Elevated Troponin) & \\
- STEMI & Primary or rescue PCI or IV Fibrinolytic (ex: tPA) \\
- NSTEMI & Early invasive strategy-PCI in high risk patients \\
& Anti-ischemic therapy: BB, CCB and nitrates \\
& IV anticoagulation: LMWH/UFH (therapeutic dose) \\
& Antiplatelet therapy (dual therapy if no contraindications) \\
- Myocarditis & Oxygen, Cautious IV hydration, Supportive care \\
& IV steroids, antiviral and anti-inflammatory agents (trials) \\
\hline Acute Circulatory Shock & (Target MAP - 60-65 mm Hg) \\
- Cardiogenic & Coronary angiography, Inotrope: Norepinephrine, MCS \\
- Systemic / Sepsis & Antiviral / anti-inflammatory agents \\
& Biological immunomodulators \\
\end{tabular}

Acute Heart Failure
- HFpEF
- HFrEF

- HFrEF
Oxygen, IV diuretic, Supportive care

Oxygen, IV diuretic, Inotrope: Dobutamine

Guideline directed medications: BB, ACE-I (as tolerated)

Renal replacement therapy(as indicated)

\section{Cardiac Arrhythmia}

- Atrial Fibrillation/Flutter

- Ventricular Tachycardia (VT)

- Polymorphic VT/VF/Tdp

- Brady arrhythmia

\section{Cardiomyopathy \\ - Stress Cardiomyopathy \\ - RV dysfunction}

\section{Vascular Thrombosis}

- VTE/ Pulmonary embolism

- Cerebrovascular accident
Hemodynamic Instability: Electrical Cardioversion

IV Amiodarone for rhythm/rate control

Rate control agents: BB and CCB / Digoxin

Therapeutic LWMH/UFH and DOAC per $\mathrm{CHA}_{2} \mathrm{DS}_{2}$-VASc (Avoid AAD and check drug interactions)

Hemodynamic Instability: Electrical Cardioversion

IV Amiodarone for rhythm control

Correct electrolytes, volume and acidosis

IV BB-Esmolol/IV Lidocaine if refractory or recurrent

$$
\text { Electrical Cardioversion }
$$

Withdrawal of all QT prolonging agents

IV Magnesium and correct electrolytes

IV Isoprenaline or Temporary Pacemaker

Remove offending agents

IV Isoprenaline, IV Atropine, Temporary Pacemaker

Oxygen, Anti Inflammatory, Inotrope: Norepinephrine

Higher preload (CVP 12-15), Ventilation, IV fluids,

Inotrope: Dopamine / Milrinone, MCS: Impella $\mathrm{RP}^{\circledR}$

Anticoagulation: Therapeutic LMWH/UFH and DOAC

IV or catheter directed (EKOS) thrombolytic (ex: tPA)

Thrombectomy with stent placement

IV thrombolysis, DOAC and antiplatelet therapies

STEMI: ST-elevation myocardial infarction, NSTEMI: Non-ST elevation myocardial infarction, PCI: Percutaneous coronary intervention, IV: intravenous, tPA: Tissue plasminogen activator, BB: Beta blocker, CCB: Calcium channel blockers, LMWH: Low-molecular-weight heparin, UFH: Unfractionated heparin, MAP: Mean arterial pressure, MCS: Mechanical circulatory support, ECMO: Extracorporeal membrane oxygenation, HFpEF: Heart failure with preserved ejection fraction, HFrEF: Heart failure with reduced ejection fraction, AAD: Anti-arrhythmic drug, Tdp: Torsade de pointes, ACE-I: Angiotensin converting enzyme inhibitor, CVP: Central venous pressure, EKOS: Ekosonic Endovascular System, DOAC: Direct oral anticoagulant, VTE: Venous thromboembolism, VF: ventricular fibrillation, $\mathrm{CHA}_{2} \mathrm{DS}_{2}$-VASC: score for atrial fibrillation stroke risk 


\subsection{Cardiac arrhythmia}

Cardiac arrhythmia is another common CV manifestation of COVID-19 infection. A preliminary patient cohort studied in Wuhan, China, reported an incidence of arrhythmia of $16.7 \%$ overall that spiked to $44 \%$ in ICU patients (Wang et al., 2020). Tachycardia and rarely bradyarrhythmia have been reported, with sinus tachycardia being the most common (Bhatla et al., 2020). Other pathological arrhythmias like atrial fibrillation, supraventricular tachycardia (SVT) and monomorphic or polymorphic ventricular tachycardia can also occur, especially in the setting of severe cardiac injury (Guo et al., 2020; Wang et al., 2020). Antiviral therapy and underlying electrolyte abnormalities can lead to QT prolongation that may increase the risk of ventricular arrhythmia, including the incidence of torsade de pointes (TdP) (Guo et al., 2020; Wang et al., 2020). An initial case report suggests that COVID-19 infection alone may also be capable of QTc prolongation through a currently unknown mechanism (Merino et al., 2020). The direct effects of COVID-19 infection on QTc interval prolongation are being investigated in ongoing clinical trials (Zaballos, 2020).

\subsection{Vascular thrombosis}

Thrombotic complications can be as high as $31 \%$ in critically ill COVID-19 patients (Klok et al., 2020a). The manifestations include venous thromboembolism (VTE), pulmonary embolism (PE) and large vessel cerebrovascular accident (CVA), especially among young adults (Klok et al., 2020b). PE was the most frequent thrombotic complication despite the use of thromboprophylaxis, especially among ICU patients (Klok et al., 2020b). For patients with suspected CVA, $31 \%$ had ischemic stroke, $6 \%$ had intracranial hemorrhage and $2 \%$ had cerebral venous thrombosis (Mahammedi et al., 2020). In addition, high risk of clotting of renal replacement circuits and device thrombosis has also been reported (Klok et al., 2020b). Based on existing evidence, thromboembolic events can be seen at any stage of the infection and in noncritically ill patients (Helms et al., 2020). Markedly elevated Ddimer level is indicative of increased risk of microthrombosis that is associated with high mortality in COVID-19 infection (Helms et al., 2020). The pathogenesis of increased vascular thrombosis is not well-understood; however, potential mechanisms may include disseminated intravascular coagulation, endothelial injury, stasis secondary to immobility, pro-coagulation pathway activation and antiphospholipid antibody-mediated mechanism (Helms et al., 2020; Singhania et al., 2020). Recently, COVID-19 associated coagulopathy (CAC) has emerged as a distinct entity from sepsis-induced coagulopathy (SIC) and disseminated intravascular coagulation (DIC). Initially in CAC, there is minimal change in the patient's platelet count and prothrombin time when compared to the more significant changes that occur in SIC and DIC (Iba et al., 2020; Singhania et al., 2020). Furthermore, VTE and arterial thrombosis are more common in the course of CAC than in SIC and DIC (Iba et al., 2020). Fig. 3 is a reproduction of a previously published schematic summary of the pathophysiological mechanisms and observed clinical cardiac manifestations, as applicable to COVID-19 infection (Guzik et al., 2020).

\section{Therapeutics for CV-specific manifestations of COVID-19}

Table 1 is an outline of direct treatment options for various $\mathrm{CV}$ specific disease manifestations that have been associated with COVID-19 infection.

\subsection{Myocardial injury}

There is a wide range of etiologies that may contribute to myocardial injury in COVID-19 including plaque rupture, demand ischemia, stress cardiomyopathy or myocarditis, all resulting in elevated troponin levels. The confirmation of an acute coronary syndrome (ACS) instead of inflammatory etiology can be aided by the presence of angina, ST segment changes on ECG, and a rise and fall in troponin levels (Mahmud et al., 2020). If ACS is suspected, patients should receive standard dual antiplatelet therapy with aspirin, a P2Y12 inhibitor, heparin products (therapeutic dose for anticoagulation), beta blockers, and a high intensity statin unless contraindicated (Amsterdam et al., 2014).

Primary percutaneous coronary intervention (PCI) within 90 minutes of presentation remains the mainstay of therapy for STEMI in patients with known or suspected COVID-19 infection (Mahmud et al., 2020). The limited use of pharmacoinvasive IV fibrinolytic therapy is reserved for the minority patient group with low-risk STEMI and for healthcare facilities that lack the resources to conduct safe primary PCI. On the other hand, NSTEMI (type 2 MI) patients should receive appropriate medical therapy and selective use of invasive strategies for high-risk clinical features such as ongoing angina, unstable arrhythmia, hemodynamic instability or heart failure (Mahmud et al., 2020). Additionally, the use of rivaroxaban in combination with standard antiplatelet therapy has been demonstrated to further mitigate the risk of a fatal event occurring during the disease course of an ACS in the ATLAS ACS-2 TIMI-51 trial (O'Riordan, 2018). Furthermore, novel analysis of data from the MARINER trial has indicated that rivaroxaban may have potential for thromboprophylaxis in at-risk patients, who are discharged following hospitalization for COVID-19 (Cox, 2020). Although the standard of care for ACS should be undertaken with suspected or known COVID-19, the therapy approach should be modified based on the severity of clinical presentation, hemodynamic stability and overall risk of mortality. The use of echocardiographic imaging may assist in additional decision-making for COVID-19 patients with suspected ACS.

\subsection{Heart failure, cardiomyopathy, and shock}

In severe COVID-19 infection, acute heart failure and circulatory shock may occur, requiring the use of inotropic agents and vasopressors to maintain a mean arterial pressure greater than 60 mmHg (American College of Cardiology, 2020). Additionally, pulmonary artery catheters may be used to help guide the administration of these therapies (American College of Cardiology, 2020). In severe COVID-19 cases with refractory shock, RV failure and extreme hypoxic lung injury, extra corporeal membrane oxygenation (ECMO) or other types of mechanical circulatory support (MCS) such as Impella $\mathrm{CP}^{\circledR}$ or RP ( or intra-aortic balloon pump) can also be used (Haiduc et al., 2020). Chronic HF patients with COVID-19 infection should continue using guidelinedirected standard medical therapy (i.e. beta blockers, RAAS modulatory agents) as previously prescribed unless contraindicated by their acute illness. The results of the ongoing Colchicine Coronavirus SARS-CoV2 (COLCORONA) trial may be noteworthy 
for the potential administration of colchicine to reduce pulmonary complications and mortality in heart disease patients with COVID19 infection (Montreal Heart Institute., 2020). Furthermore, the results of The Three C Study may also yield promise with the potential use of canakinumab, an anti-inflammatory drug, to prevent acceleration of heart and respiratory failure during COVID-19 infection (The Cleveland Clinic. , 2020).

\subsection{Cardiac arrhythmia}

ARDS with hypoxia, as a result of COVID-19, may increase the risk of atrial arrhythmia including atrial fibrillation (AF) and atrial flutter (Aflutter) (Buch et al., 2003). The ongoing ACOVID trial is investigating whether the use of continuous ECG monitoring can help elucidate the mechanism by which COVID-19 contributes to the development of cardiac arrhythmia (Lamberts, 2020). While the etiological mechanism may be unknown, the goals of therapy for supraventricular arrhythmia are similar with rate control, rhythm control and thromboembolic prophylaxis. In hemodynamically unstable patients with AF, Aflutter, or VT, electrical cardioversion should be performed if intubation can be done with minimal risk of exposure to viral aerosol particles (Driggin et al., 2020; Lakkireddy et al., 2020). In hemodynamically stable patients with AF, Aflutter, or VT, IV amiodarone can be administered with consideration for risk of QT prolongation with other medications. Initiation of rate control therapy with beta or calcium channel blockers (with or without digoxin) may be considered for hemodynamically stable AF and supraventricular arrhythmia. Anticoagulation for thromboembolic and stroke prophylaxis guided by $\mathrm{CHA}_{2} \mathrm{DS}_{2}$-VASc score of greater than or equal to 2 is required, in the absence of significant risk for bleeding (January et al., 2019).

New onset VT is a marker of acute myocardial injury with COVID-19 and the incidence of the infection as a trigger of VT or VF is not known. In a cardiac arrest situation, the standard basic and advanced life support protocols are to be followed with appropriate personal protective equipment of the staff (European Society of Cardiology, 2020). Instead of amiodarone, IV procainamide or lidocaine can be considered for hemodynamically stable patients on QT prolonging antiviral agents (European Society of Cardiology, 2020). For patients with arrhythmias, there should be prompt correction of electrolytes and acidosis as well as hypoxia with intubation. In cases of recurrent VT with increased adrenergic surge, the addition of a sympathetic blockade (esmolol) can be considered. TdP, a form of polymorphic VT, is associated with QT prolongation that can be triggered by antiviral agents used in combination with cardiac medications. To manage TdP, all QT prolonging drugs should be withdrawn, electrolyte levels corrected, and bradycardia should be improved with IV isoproterenol or an overriding, temporary pacemaker (European Society of Cardiology, 2020). After recovery from COVID-19, secondary prophylactic implantable cardioverter-defibrillator or catheter ablation needs to be considered based on additional cardiac evaluation.

\subsection{Vascular thrombosis}

PE and VTE therapy depends on the clinical status and comorbidities of the patient; higher risk patients benefit more from systemic IV or catheter-directed thrombolysis via EkoSonic ${ }^{T M}$ Endovascular System (EKOS) as well as mechanical thrombectomy
(European Society of Cardiology, 2020). Low to intermediaterisk patients are mostly managed with parenteral anticoagulation with therapeutic dose heparin products, which is then followed with long-term use of Vitamin-K antagonist (VKA) or direct oral anticoagulant (DOAC) agents (Watson et al., 2020). Patients with acute thrombotic CVA benefit from early systemic thrombolytics (tissue plasminogen activator) or endovascular therapy (AHA/ASA Stroke Council Leadership, 2020). Standard secondary prevention antiplatelet therapy is to be considered for presentations of vascular thrombosis (Watson et al., 2020). Routine thromboprophylaxis with heparin products is strongly recommended in all hospitalized COVID-19 patients as it has demonstrated lower mortality when combined with antiviral agents (Tang et al., 2020). Currently, a clinical trial led by Massachusetts General Hospital is evaluating the use of enoxaparin for anticoagulation in COVID-19 patients with elevated D-dimers (Massachusetts General Hospital, 2020). Extended VTE prophylaxis with DOAC agents should be considered for critically-ill patients trying to overcome symptomatic COVID-19 (Watson et al., 2020).

\subsection{Other considerations}

Patients with mechanical prosthetic valves should continue receiving chronic VKA with warfarin and low-dose aspirin therapy (Nishimura et al., 2014). Standard bridging with therapeutic heparin is required for any interruptions with anticoagulation and mechanical prosthetic valves (Nishimura et al., 2014). For patients with chronic, stable cardiovascular disease including ischemic and valvular heart disease as well as heart failure, standard treatment should be continued even with COVID-19 infection unless directly contraindicated (European Society of Cardiology, 2020).

\section{COVID-19 therapies and their associated CV implications \\ 6.1 Antivirals}

Until recently, no specific antiviral therapy had been effective for COVID-19 and the management was largely supportive, focused on preventing symptomatic complications and organ failure. Recently, IV remdesivir became the first FDA-approved antiviral therapy with clinical improvement of hypoxic SARS-CoV-2 patients (Grein et al., 2020). Other antiviral agents and immune modulating biologicals have been used in clinical practice and are undergoing further clinical trials (Delang and Neyts, 2020). Some of these antivirals carry the risk of PR-QT interval prolongation, especially in patients with a baseline prolonged QT interval or with other QT prolonging drugs (AbbVie Inc., 2013). These drugs may have variable effects on anticoagulant warfarin dosing and may require dose reductions of CYP3A-mediated DOAC agents (DeCarolis et al., 2016; Mueck et al., 2013). As of July 2020, the World Health Organization decided to stop trials with combinations of lopinavir and ritonavir for COVID-19 therapy as the Solidarity Trial revealed these drugs had minimal reduction in patient mortality (World Health Organization. , 2020b). Antivirals can also influence the activity of P2Y12inhibitors, resulting in altered serum concentrations of the active metabolites of antiplatelet agents (decreased for clopidogrel and prasugrel while increased for ticagrelor) (AstraZeneca Canada Inc., 2011). As a result, there will need to be careful monitoring with possible dose adjustments for anticoagulant and/or antiplatelet therapy given to COVID-19 
patients.

\subsection{Chloroquine}

Chloroquine, an antimalarial agent, blocks viral infection by increasing the endosomal $\mathrm{pH}$ in vitro, however, closely-related hydroxychloroquine has been shown to have limited benefits in the treatment of COVID-19 (Geleris et al., 2020). Potential risks of chloroquine use include cardiac toxicity with direct myocardial suppression and altered cardiac conduction, including the risk of QT prolongation and associated ventricular arrhythmia (Driggin et al., 2020). In addition, due to its effects on CYP2D6 inhibition, chloroquine may cause increased concentration of concurrent beta blocker levels, requiring monitoring of heart rate and blood pressure with appropriate dose adjustments (Tönnesmann et al., 2013).

\subsection{RAAS modulators (ARB, ACE inhibitors, aldosterone blockers}

Controversy exists over the use of RAAS modulators such as ACE inhibitors or ANG II receptor blocker (ARB) agents in the treatment of COVID-19. In rat models, ACE inhibitor agent lisinopril increased ACE2 activity and ARB agents losartan and eprosartan caused a twofold increase in ACE2 activity (South et al., 2020). Since these agents upregulate ACE2 peptidase levels, they may increase the risk of viral entry in bronchial epithelial cells (Brett and Rind, 2020). Contrarily, ACE inhibitors have been demonstrated to increase ANG-(1-7) levels while decreasing ANG II levels, which is beneficial for cardiothoracic tissues due to the antifibrotic and anti-inflammatory effects of ANG-(1-7) (Chappell, 2016). It has been demonstrated that in human kidney organoids, human recombinant soluble ACE2 (hrsACE2) can be used to prevent SARS-CoV-2 viral entry into host cells during the early stages of infection by competitively binding the viral spike protein (Monteil et al., 2020) (see Fig. 1) (Guzik et al., 2020). Furthermore, the activation of ADAM metallopeptidase domain 17 (ADAM17) with disintegrin can free ACE2 that is membrane-bound, which then acts as soluble ACE2 that may hinder viral entry into the host cell (see Fig. 1) (Guzik et al., 2020). However, the ACE2 shedding mechanism by which ADAM17 may prevent COVID-19 infection needs further evaluation (Palau et al., 2020). Aldosterone antagonists, including spironolactone and eplerenone, may have a dual therapeutic mechanism by 1) inhibiting activation of the mineralocorticoid receptor (MR) that promotes the hyperinflammatory profile responsible for ARDS in COVID-19 and 2) inhibiting TMPRSS2 expression, which is essential for activation of the spike protein used in viral entry (Liaudet and Szabo, 2020). Theoretically, aldosterone antagonists may have a beneficial effect in preventing lung injury from COVID-19, however; their benefits in the CV system still remains undetermined. Although there are arguments for and against RAAS modulator use in COVID-19 patients, there is insufficient evidence to stop the use of these agents for hypertension control and any other standard indications during concurrent COVID-19 infection (Mancia et al., 2020).

\subsection{Corticosteroids}

Recent data from the Randomised Evaluation of COVID-19 therapy (RECOVERY) trial suggest that there is a favorable benefit in the use of low-dose dexamethasone for COVID-19 patients with hypoxic respiratory failure (Horby et al., 2020). It is important to note the use of low dose dexamethasone to avoid the immunosup- pressive effects of higher doses. However, steroid therapy has an increased risk for fluid retention, electrolyte imbalances, hypertension exacerbation and interaction with warfarin that needs additional monitoring (Hodgens and Sharman, 2020). Glucocorticoids have been shown to suppress the release of pro-inflammatory cytokines involved in the cytokine storm during COVID-19 infection (Cruz-Topete and Cidlowski, 2015). The use of steroids was numerically higher for patients with myocardial injury who survived COVID-19 infection, although this treatment should not be routine and should instead be considered salvage therapy for hemodynamically unstable patients (Zhou et al., 2020).

\section{Conclusions}

As the SARS-CoV-2 pandemic progresses, the interactions between co-existing $\mathrm{CV}$ disease and acute $\mathrm{CV}$ manifestations have a major implication on the medical community's understanding of this disease. The heart and vascular manifestations are more likely to be associated with severe disease resulting in adverse outcomes including increased mortality. Early recognition and a widespread in-depth understanding of the spectrum of $\mathrm{CV}$ conditions will help prioritize therapy and improve disease prognosis. The scientific community continues to learn key new insights about pathogenesis and therapeutics from current ongoing clinical trials. This will evolve over time to further improve the extent of favorable outcomes for patients infected during this pandemic. As our current gap in knowledge of this disease narrows, the lessons learnt will likely emerge to provide us a new paradigm of understanding, therapeutics and healthcare models even after this crisis is over.

\section{Authors' contributions}

A.M.1 and J.M.1 conceived the original idea and structure for this review manuscript. A.M.1 and A.M.2 were responsible for collection and analysis of the primary research articles used as well as for creating the draft of the review. J.M.1 supervised the accuracy of analysis as well as comprehensiveness of research articles included in the review manuscript. A.M.1, A.M.2, J.M.1 did the final proofing of the manuscript for correct spelling, grammar, reference formatting, and accuracy of the content in each section.

\section{Acknowledgments}

The authors would like to thank Dr. Rathi Mahendran for her assistance with selection of key sections for the focus of the manuscript as well as her comments on analysis of primary research articles in this review manuscript.

\section{Conflict of interest}

The authors declare no conflicts of interest statement.

Submitted: July 02, 2020

Revised: August 06, 2020

Accepted: August 07, 2020

Published: September 30, 2020

\section{References}

AHA/ASA Stroke Council Leadership (2020) Temporary emergency guidance to US Stroke Centers during the Coronavirus disease 2019 (COVID-19) pandemic. Stroke 51, 1910-1912.

Akhmerov, A. and Marbán, E. (2020) COVID-19 and the heart. Circulation Research 126, 1443-1455. 
American College of Cardiology. (2020) Key questions on COVID-19 and cardiovascular disease. Available at: https: //www.acc.org/ /media/Non-Clinical/Files-PDFs-Excel -MS-Word-etc/2020/04/30/S20057-Key-Questions-COV ID-19-CV-Disease-FINAL-UPLOADED-April-30-2020.pdf (Accessed: April 30, 2020)

Amsterdam, E. A., Wenger, N. K., Brindis, R. G., Casey, D. E., Ganiats, T. G., Holmes, D. R., Jaffe, A. S., Jneid, H., Kelly, R. F., Kontos, M. C., Levine, G. N., Liebson, P. R., Mukherjee, D., Peterson, E. D., Sabatine, M. S., Smalling, R. W. and Zieman, S. J. (2014) 2014 AHAACC guideline for the management of patients with non-ST-elevation acute coronary syndromes. Journal of the American College of Cardiology 64, e139-e228.

Arentz, M., Yim, E., Klaff, L., Lokhandwala, S., Riedo, F. X., Chong, M. and Lee, M. (2020) Characteristics and outcomes of 21 critically Ill Patients with COVID-19 in Washington State. JAMA 323, 1612.

Bangalore, S., Sharma, A., Slotwiner, A., Yatskar, L., Harari, R., Shah, B., Ibrahim, H., Friedman, G. H., Thompson, C., Alviar, C. L., Chadow, H. L., Fishman, G. I., Reynolds, H. R., Keller, N. and Hochman, J. S. (2020) ST-segment elevation in patients with Covid-19 — a case series. New England Journal of Medicine 382, 2478-2480.

Bhatla, A., Mayer, M. M., Adusumalli, S., Hyman, M. C., Oh, E., Tierney, A., Moss, J., Chahal, A. A., Anesi, G., Denduluri, S., Domenico, C. M., Arkles, J., Abella, B. S., Bullinga, J. R., Callans, D. J., Dixit, S., Epstein, A. E., Frankel, D. S., Garcia, F. C., Kumareswaram, R., Nazarian, S., Riley, M. P., Santangeli, P., Schaller, R. D., Supple, G. E., Lin, D., Marchlinski, F. and Deo, R. (2020) COVID-19 and cardiac arrhythmias. Heart Rhythm (in press).

Brett, A. S.and Rind, D. M. (2020) ACE inhibitors and ARBs during the COVID-19 pandemic. The New England Journal of Medicine Journal Watch. Available at: https://www.jwatch.org/na51345/2020/ 04/09/ace-inhibitors-and-arbs-during-covid-19-pandemic (Accessed: April 9, 2020).

AstraZeneca Canada Inc. (2011) Brilinta (Ticagrelor) [Product monograph]. Mississauga, ON.

Buch, P., Friberg, J., Scharling, H., Lange, P. and Prescott, E. (2003) Reduced lung function and risk of atrial fibrillation in The Copenhagen City Heart Study. European Respiratory Journal 21, 1012-1016

Chappell, M. C. (2016) Biochemical evaluation of the renin-angiotensin system: the good, bad, and absolute? American Journal of PhysiologyHeart and Circulatory Physiology 310, H137-H152.

Cox, C. E. (2020) Rivaroxaban may yet Protect after a hospital stay. MARINER. TCTMD - Cardiovascular Research Foundation. Available at: https://www.tctmd.com/news/rivaroxaban-may-yet - protect-after-hospital-stay-mariner (Accessed: June 25, 2020)

Cruz-Topete, D. and Cidlowski, J. A. (2015) One Hormone, Two Actions: Anti- and Pro-Inflammatory Effects of Glucocorticoids. Neuroimmunomodulation $\mathbf{2 2}, 20-32$.

DeCarolis, D. D., Westanmo, A. D., Chen, Y., Boese, A. L., Walquist, M. A. and Rector, T. S. (2016) Evaluation of a potential interaction between new regimens to treat hepatitis $\mathrm{C}$ and warfarin. Annals of Pharmacotherapy 50, 909-917.

Delang, L. and Neyts, J. (2020) Medical treatment options for COVID-19. European Heart Journal: Acute Cardiovascular Care 9, 209-214.

Driggin, E., Madhavan, M. V., Bikdeli, B., Chuich, T., Laracy, J., BiondiZoccai, G., Brown, T. S., Der Nigoghossian, C., Zidar, D. A., Haythe, J., Brodie, D., Beckman, J. A., Kirtane, A. J., Stone, G. W., Krumholz, H. M. and Parikh, S. A. (2020) Cardiovascular considerations for patients, health care workers, and health systems during the COVID-19 pandemic. Journal of the American College of Cardiology 75, 23522371.

Ellinghaus, D., Degenhardt, F., Bujanda, L., Buti, M., Albillos, A., Invernizzi, P., Fernández, J., Prati, D., Baselli, G., Asselta, R. et al. (2020) Genomewide association study of severe Covid-19 with respiratory failure. The New England Journal of Medicine (in press).

European Society of Cardiology. (2020) ESC Guidance for the Diagnosis and Management of CV Disease during the COVID-19 Pandemic. Available at: https://www.escardio.org/static-file/Escardio/E ducation-General/Topic\%20pages/Covid-19/ESC\%20Guida
nce\%20Document/ESC-Guidance-COVID-19-Pandemic.pdf (Accessed: June 10, 2020)

Fried, J. A., Ramasubbu, K., Bhatt, R., Topkara, V. K., Clerkin, K. J., Horn, E., Rabbani, L., Brodie, D., Jain, S. S., Kirtane, A. J., Masoumi, A., Takeda, K., Kumaraiah, D., Burkhoff, D., Leon, M., Schwartz, A., Uriel, N. and Sayer, G. (2020) The variety of cardiovascular presentations of COVID-19. Circulation 141, 1930-1936.

Ge, X., Li, J., Yang, X., Chmura, A. A., Zhu, G., Epstein, J. H., Mazet, J. K., Hu, B., Zhang, W., Peng, C., Zhang, Y., Luo, C., Tan, B., Wang, N., Zhu, Y., Crameri, G., Zhang, S., Wang, L., Daszak, P. and Shi, Z. (2013) Isolation and characterization of a bat SARS-like coronavirus that uses the ACE2 receptor. Nature 503, 535-538.

Geleris, J., Sun, Y., Platt, J., Zucker, J., Baldwin, M., Hripcsak, G., Labella, A., Manson, D. K., Kubin, C., Barr, R. G., Sobieszczyk, M. E. and Schluger, N. W. (2020) Observational study of hydroxychloroquine in hospitalized patients with Covid-19. New England Journal of Medicine 382, 2411-2418.

Grein, J., Ohmagari, N. and Shin, D. (2020) Compassionate use of remdesivir for patients with severe Covid-19. The New England Journal of Medicine 382, 2327-2336.

Guan, W. J., Ni, Z. Y., Hu, Y., Liang, W. H., Ou, C. Q., He, J. X., Liu, L., Shan, H. Lei, C. L. et al. and Zhong, N. S. (2020) Clinical characteristics of coronavirus disease 2019 in China. New England Journal of Medicine 382, 1708-1720.

Guo, T., Fan, Y., Chen, M., Wu, X., Zhang, L., He, T., Wang, H., Wan, J., Wang, X. and Lu, Z. (2020) Cardiovascular implications of fatal outcomes of patients with Coronavirus disease 2019 (COVID-19). JAMA Cardiology 5, 811

Gupta, A. K., Jneid, H., Addison, D., Ardehali, H., Boehme, A. K., Borgaonkar, S., Boulestreau, R., Clerkin, K., Delarche, N., DeVon, H. A., Grumbach, I. M., Gutierrez, J., Jones, D. A., Kapil, V., Maniero, C., Mentias, A., Miller, P. S., Ng, S. M., Parekh, J. D., Sanchez, R. H., Sawicki, K. T., Riele, A. S. J. M. t., Remme, C. A. and London, B. (2020) Current perspectives on Coronavirus disease 2019 and cardiovascular disease: a white paper by the JAHA editors. Journal of the American Heart Association 9, e017013.

Guzik, T. J., Mohiddin, S. A., Dimarco, A., Patel, V., Savvatis, K., Marelli-Berg, F. M., Madhur, M. S., Tomaszewski, M., Maffia, P., D’Acquisto, F., Nicklin, S. A., Marian, A. J., Nosalski, R., Murray, E. C., Guzik, B., Berry, C., Touyz, R. M., Kreutz, R., Wang, D. W., Bhella, D., Sagliocco, O., Crea, F., Thomson, E. C., McInnes, I. B. (2020) COVID-19 and the cardiovascular system: implications for risk assessment, diagnosis, and treatment options. Cardiovascular Research 116, 1666-1687.

Haiduc, A. A., Alom, S., Melamed, N., Harky, A. (2020) Role of extracorporeal membrane oxygenation in COVID-19: A systematic review. Journal of Cardiac Surgery (in press).

Xu, H., Zhong, L., Deng, J., Peng, J., Dan, H., Zeng, X., Li, T. and Chen, Q. (2020) High expression of ACE2 receptor of 2019-nCoV on the epithelial cells of oral mucosa. International Journal of Oral Science 12,8 .

He, F., Deng, Y. and Li, W. (2020) Coronavirus disease 2019: What we know? Journal of Medical Virology 92, 719-725.

Helms, J., CRICS TRIGGERSEP Group (Clinical Research in Intensive Care and Sepsis Trial Group for Global Evaluation and Research in Sepsis), Tacquard, C., Severac, F., Leonard-Lorant, I., Ohana, M., Delabranche, X., Merdji, H., Clere-Jehl, R., Schenck, M., Fagot Gandet, F., Fafi-Kremer, S., Castelain, V., Schneider, F., Grunebaum, L., Anglés-Cano, E., Sattler, L., Mertes, P. and Meziani, F. (2020) High risk of thrombosis in patients with severe SARS-CoV-2 infection: a multicenter prospective cohort study. Intensive Care Medicine 46, 1089-1098.

Lamberts, M. and Herlev and Gentofte Hospital. (2020) Arrhythmias in patients with COVID-19 (ACOVID). Available at: https://clinical trials.gov/ct2/show/NCT04395664 (Accessed: May 20, 2020)

Hodgens, A. and Sharman, T. (2020) Corticosteroids. StatPearls. Treasure Island (FL): StatPearls Publishing. 
Hoffmann, M., Kleine-Weber, H., Schroeder, S., Krüger, N., Herrler, T., Erichsen, S., Schiergens, T. S., Herrler, G., Wu, N., Nitsche, A., Müller, M. A., Drosten, C. and Pöhlmann, S. (2020) SARS-CoV-2 cell entry depends on ACE2 and TMPRSS2 and is blocked by a clinically proven protease inhibitor. Cell 181, 271-280.e8.

Horby, P., Lim, W. S., Emberson, J., Mafham, M., Bell, J., Linsell, L., Staplin, N., Brightling, C., Ustianowski, A., Elmahi, E., Prudon, B., Green, C., Felton, T., Chadwick, D., Rege, K., Fegan, C., Chappell, L. C., Faust, S. N., Jaki, T., Jeffery, K., Montgomery, A., Rowan, K., Juszczak, E., Baillie, J. K., Haynes, R. and Landray, M. J. (2020) Effect of dexamethasone in hospitalized patients with COVID-19: Preliminary Report. medRxiv (in press).

Huang, C., Wang, Y., Li, X., Ren, L., Zhao, J., Hu, Y., Zhang, L., Fan, G., Xu, J., Gu, X., Cheng, Z., Yu, T., Xia, J., Wei, Y., Wu, W., Xie, X., Yin, W., Li, H., Liu, M., Xiao, Y., Gao, H., Guo, L., Xie, J., Wang, G., Jiang, R., Gao, Z., Jin, Q., Wang, J. and Cao, B. (2020) Clinical features of patients infected with 2019 novel coronavirus in Wuhan, China. the Lancet 395, 497-506.

Iba, T., Levy, J. H., Connors, J. M., Warkentin, T. E., Thachil, J. and Levi, M. (2020) The unique characteristics of COVID-19 coagulopathy. Critical Care 24, 360.

January, C. T., Wann, L. S., Calkins, H., Chen, L. Y., Cigarroa, J. E., Cleveland, J. C., Jr, Ellinor, P. T., Ezekowitz, M. D., Field, M. E., Furie, K. L., Heidenreich, P. A., Murray, K. T., Shea, J. B., Tracy, C. M. and Yancy, C. W. (2019) 2019 AHA/ACC/HRS Focused Update of the $2014 \mathrm{AHA} / \mathrm{ACC} / \mathrm{HRS}$ Guideline for the management of patients with atrial fibrillation: A report of the American College of Cardiology/American Heart Association task force on clinical practice guidelines and the heart rhythm society. Journal of the American College of Cardiology 74, 104-132.

Januzzi, J. L. (2020) Troponin and BNP use in COVID-19. Available at: https://www.acc.org/latest-in-cardiology/articles/2020/03/ 18/15/25/troponin-and-bnp-use-in-covid19 (Accessed: March $18,2020)$.

Johns Hopkins University. (2020) COVID-19 dashboard by the Center for Systems Science and Engineering (CSSE) at Johns Hopkins University (JHU). Available at: https://coronavirus.jhu.edu/map.html (Accessed: July 19, 2020).

AbbVie Inc. (per FDA). (2013) KALETRA(R) oral film coated tablets, oral solution, lopinavir ritonavir oral film coated tablets, oral solution [Package insert]. North Chicago, IL.

Kim, D. J. (2020) COVID-19 and point of care echocardiography. Clarius Mobile Health. Available at: https://clarius.com/covid-19-and-p oint-of-care-echocardiography/ (Accessed: May 3, 2020).

Klok, F. A., Kruip, M. J. H. A., van der Meer, N. J. M., Arbous, M. S., Gommers, D., Kant, K. M., Kaptein, F. H. J., van Paassen, J., Stals, M. A. M., Huisman, M. V. and Endeman, H. (2020a) Confirmation of the high cumulative incidence of thrombotic complications in critically ill ICU patients with COVID-19: An updated analysis. Thrombosis Research 191, 148-150.

Klok, F. A., Kruip, M. J. H. A., van der Meer, N. J. M., Arbous, M. S., Gommers, D. A. M. P. J., Kant, K. M., Kaptein, F. H. J., van Paassen, J., Stals, M. A. M., Huisman, M. V. and Endeman, H. (2020b) Incidence of thrombotic complications in critically ill ICU patients with COVID19. Thrombosis Research 191, 145-147.

Lakkireddy, D. R., Chung, M. K., Gopinathannair, R., Patton, K. K., Gluckman, T. J., Turagam, M., Cheung, J., Patel, P., Sotomonte, J., Lampert, R., Han, J. K., Rajagopalan, B., Eckhardt, L., Joglar, J., Sandau, K., Olshansky, B., Wan, E., Noseworthy, P. A., Leal, M., Kaufman, E., Gutierrez, A., Marine, J. M., Wang, P. J. and Russo, A. M. (2020) Guidance for Cardiac Electrophysiology During the COVID19 Pandemic from the Heart Rhythm Society COVID-19 Task Force; Electrophysiology Section of the American College of Cardiology; and the Electrocardiography and Arrhythmias Committee of the Council on Clinical Cardiology, American Heart Association. Heart Rhythm (in press).

Li, Q., Guan, X., Wu, P., Wang, X., Zhou, L., Tong, Y., Ren, R., Leung, K. S. M., Lau, E. H. Y., Wong, J. Y., et al. (2020) Early Transmission Dynamics in Wuhan, China, of Novel Coronavirus-Infected Pneumonia.
New England Journal of Medicine 382, 1199-1207.

Liaudet, L. and Szabo, C. (2020) Blocking mineralocorticoid receptor with spironolactone may have a wide range of therapeutic actions in severe COVID-19 disease. Critical Care 24, 318.

Mahammedi, A., Saba, L., Vagal, A., Leali, M., Rossi, A., Gaskill, M., Sengupta, S., Zhang, B., Carriero, A., Bachir, S., Crivelli, P., Paschè, A., Premi, E., Padovani, A. and Gasparotti, R. (2020) Imaging in neurological disease of hospitalized COVID-19 patients: an italian multicenter retrospective observational study. Radiology (in press).

Mahmud, E., Dauerman, H. L., Welt, F. G., Messenger, J. C., Rao, S. V., Grines, C., Mattu, A., Kirtane, A. J., Jauhar, R., Meraj, P., Rokos, I. C., Rumsfeld, J. S. and Henry, T. D. (2020) Management of acute myocardial infarction during the COVID-19 pandemic. Journal of the American College of Cardiology (in press).

Mancia, G., Rea, F., Ludergnani, M., Apolone, G. and Corrao, G. (2020) Renin-Angiotensin-Aldosterone system blockers and the risk of Covid-19. New England Journal of Medicine 382, 2431-2440.

Massachusetts General Hospital. (2020) Safety and efficacy of therapeutic anticoagulation on clinical outcomes in hospitalized patients with COVID-19. Available at: https://clinicaltrials.gov/ct2/show/N CT04377997 (Accessed: May 7, 2020)

Mehra, M. R. and Ruschitzka, F. (2020) COVID-19 Illness and Heart Failure. JACC: Heart Failure 8, 512-514.

Merino, J. L., Martínez-Cossiani, M., Iniesta, A., Escobar, C., Rey, J. R. and Castrejón-Castrejón, S. (2020) COVID-19 and QT interval prolongation: more than just drug toxicity? Ep Europace (in press).

Dabbagh, M. F., Aurora, L., D’Souza, P., Weinmann, A. J., Bhargava, P. and Basir, M. B. (2020) Cardiac tamponade secondary to COVID-19. JACC: Case Reports 2, 1326-1330.

Monteil, V., Kwon, H., Prado, P., Hagelkrüys, A., Wimmer, R. A., Stahl, M., Leopoldi, A., Garreta, E., Hurtado del Pozo, C., Prosper, F., Romero, J. P., Wirnsberger, G., Zhang, H., Slutsky, A. S., Conder, R., Montserrat, N., Mirazimi, A. and Penninger, J. M. (2020) Inhibition of SARS-CoV-2 infections in engineered human tissues using clinicalgrade soluble human ACE2. Cell 181, 905-913.e7.

Montreal Heart Institute. (2020) Colchicine coronavirus SARS-CoV2 trial (COLCORONA) (COVID-19). Available at: https://clinicaltrials .gov/ct2/show/NCT04322682 (Accessed: March 26, 2020).

Mueck, W., Kubitza, D. and Becka, M. (2013) Co-administration of rivaroxaban with drugs that share its elimination pathways: pharmacokinetic effects in healthy subjects. British Journal of Clinical Pharmacology 76, 455-466.

Nishimura, R. A., Otto, C. M., Bonow, R. O., Carabello, B. A., Erwin, J. P., Guyton, R. A., O’Gara, P. T., Ruiz, C. E., Skubas, N. J., Sorajja, P., Sundt, T. M. and Thomas, J. D. (2014) 2014 AHA/ACC Guideline for the management of patients with valvular heart disease: executive summary. Circulation 129, 2440-2492.

O'Riordan, M. (2018) Rivaroxaban offers net reduction in fatal or irreversible events in ACS: ATLAS ACS-2 TIMI-51. TCTMD - Cardiovascular Research Foundation. Available at: https://www.tctmd.com/news/rivaroxaban-offers-net-red uction-fatal-or-irreversible-events-acs-atlas-acs-2-timi- 51 (Accessed: July 06, 2018).

Pal, M., Berhanu, G., Desalegn, C. and Kandi, V. (2020) Severe acute respiratory syndrome Coronavirus-2 (SARS-CoV-2): An Update. Cureus 12, e7423.

Palau, V., Riera, M. and Soler, M. J. (2020) ADAM17 inhibition may exert a protective effect on COVID-19. Nephrology Dialysis Transplantation 35, 1071-1072.

Richardson, S., Donald and Barbara Zucker School of Medicine at HofstraNorthwell, Northwell Health, Hempstead, New York, Hirsch, J. S., Donald and Barbara Zucker School of Medicine at HofstraNorthwell, Northwell Health, Hempstead, New York, Department of Information Services, Northwell Health, New Hyde Park, New York, Narasimhan, M., Crawford, J. M., McGinn, T., Donald and Barbara Zucker School of Medicine at HofstraNorthwell, Northwell Health, Hempstead, New York, Davidson, K. W., et al. (2020) Presenting characteristics, comorbidities, and outcomes among 5700 patients hospitalized with COVID19 in the New York city area. JAMA 323, 2052. 
Sharma, A., Garcia, G., Wang, Y., Plummer, J. T., Morizono, K., Arumugaswami, V. and Svendsen, C. N. (2020) Human iPSC-derived cardiomyocytes are susceptible to SARS-CoV-2 infection. Cell Reports Medicine 1, 100052

Singhania, N., Bansal, S., Nimmatoori, D. P., Ejaz, A. A., McCullough, P. A. and Singhania, G. (2020) Current overview on hypercoagulability in COVID-19. American Journal of Cardiovascular Drugs (in press).

South, A. M., Diz, D. I. and Chappell, M. C. (2020) COVID-19, ACE2, and the cardiovascular consequences. American Journal of PhysiologyHeart and Circulatory Physiology 318, H1084-H1090.

Stokes, E. K., Zambrano, L. D., Anderson, K. N., Marder, E. P., Raz, K. M., El Burai Felix, S., Tie, Y. and Fullerton, K. E. (2020) Coronavirus disease 2019 case surveillance - United States, January 22-May 30, 2020. Mmwr. Morbidity and Mortality Weekly Report 69, 759-765.

Szekely, Y., Lichter, Y., Taieb, P., Banai, A., Hochstadt, A., Merdler, I., Gal Oz, A., Rothschild, E., Baruch, G., Peri, Y., Arbel, Y. and Topilsky, Y. (2020) Spectrum of cardiac manifestations in COVID-19. Circulation 142, 342-353.

Tang, N., Bai, H., Chen, X., Gong, J., Li, D. and Sun, Z. (2020) Anticoagulant treatment is associated with decreased mortality in severe coronavirus disease 2019 patients with coagulopathy. Journal of Thrombosis and Haemostasis 18, 1094-1099.

Tavazzi, G., Pellegrini, C., Maurelli, M., Belliato, M., Sciutti, F., Bottazzi, A., Sepe, P. A., Resasco, T., Camporotondo, R., Bruno, R., Baldanti, F., Paolucci, S., Pelenghi, S., Iotti, G. A., Mojoli, F. and Arbustini, E. (2020) Myocardial localization of coronavirus in COVID-19 cardiogenic shock. European Journal of Heart Failure 22, 911-915.

The Cleveland Clinic. (2020) Canakinumab in Covid-19 cardiac injury (The Three C Study). Available at: https://clinicaltrials.gov/ct2/ show/NCT04365153 (Accessed: April 28, 2020).

Tönnesmann, E., Kandolf, R. and Lewalter, T. (2013) Chloroquine cardiomyopathy - a review of the literature. Immunopharmacology and
Immunotoxicology 35, 434-442.

Wang, D., Hu, B., Hu, C., Zhu, F., Liu, X., Zhang, J., Wang, B., Xiang, H., Cheng, Z., Xiong, Y., Zhao, Y., Li, Y., Wang, X. and Peng, Z. (2020) Clinical characteristics of 138 hospitalized patients with 2019 novel Coronavirus-infected pneumonia in Wuhan, China. JAMA 323, 1061.

Watson, R. A., Johnson, D. M., Dharia, R. N., Merli, G. J. and Doherty, J. U. (2020) Anti-coagulant and anti-platelet therapy in the COVID-19 patient: a best practices quality initiative across a large health system. Hospital Practice 394, 1-11.

World Health Organization. (2020a) Novel Coronavirus (2019-nCoV) situation report, 11. Available at: https://apps.who.int/iris/handle /10665/330776 (Accessed: January 31, 2020)

World Health Organization. (2020b) WHO discontinues hydroxychloroquine and lopinavir/ritonavir treatment arms for COVID-19. Available at: https://www.who.int/news-room/detail/04-07-2020-who -discontinues-hydroxychloroquine-and-lopinavir-ritonavir- $t$ reatment-arms-for-covid-19 (Accessed: July 4, 2020).

$\mathrm{Wu}, \mathrm{Z}$. and McGoogan, J. M. (2020) Characteristics of and important lessons from the coronavirus disease 2019 (COVID-19) Outbreak in China. JAMA 323, 1239.

Zaballos, M. (2020) Effects on the Qt interval of COVID-19 coronavirus infection (QT-COVID-19). Available at: https://clinicaltrials.gov /ct2/show/NCT04422535 (Accessed: June 9, 2020).

Zhang, T., Wu, Q. and Zhang, Z. (2020) Probable pangolin origin of SARS-CoV-2 associated with the COVID-19 outbreak. Current Biology 30, 1346-1351.e2.

Zhou, F., Yu, T., Du, R., Fan, G., Liu, Y., Liu, Z., Xiang, J., Wang, Y., Song, B., Gu, X., Guan, L., Wei, Y., Li, H., Wu, X., Xu, J., Tu, S., Zhang, Y., Chen, H. and Cao, B. (2020) Clinical course and risk factors for mortality of adult inpatients with COVID-19 in Wuhan, China: a retrospective cohort study. The Lancet 395, 1054-1062. 